\title{
Prevalence of vitamin D deficiency and secondary hyperparathyroidism during winter in pre-menopausal Bangladeshi and Somali immigrant and ethnic Finnish women: associations with forearm bone mineral density
}

\author{
Md Zahirul Islam ${ }^{1}$, Heli T. Viljakainen ${ }^{1}$, Merja U. M. Kärkkäinen ${ }^{1}$, Elisa Saarnio ${ }^{1}$, Kalevi Laitinen ${ }^{2}$ \\ and Christel Lamberg-Allardt ${ }^{1 *}$ \\ ${ }^{1}$ Calcium Research Unit, Department of Food and Environmental Sciences (Nutrition), University of Helsinki, PO Box 66, \\ oO014 Helsinki, Finland \\ ${ }^{2}$ Faculty of Medicine, University of Helsinki, PO Box 20, O0029 Helsinki, Finland
}

(Received 2 September 2010 - Revised 26 April 2011 - Accepted 26 April 2011 - First published online 9 August 2011)

\section{Abstract}

Secondary hyperparathyroidism (SHPT) is one of the outcomes of vitamin D deficiency that negatively affects bone metabolism. We studied the ethnic differences in vitamin D status in Finland and its effect on serum intact parathyroid hormone (S-iPTH) concentration and bone traits. The study was done in the Helsinki area $\left(60^{\circ} \mathrm{N}\right)$ during January-February 2008 . A total of 143 healthy women $(20-48$ years of age) from two groups of immigrant women (Bangladeshi, $n 34$ and Somali, $n$ 48), and a group of ethnic Finnish women ( $n$ 61) were studied in a cross-sectional setting. Serum concentrations of 25-hydroxyvitamin D (S-25OHD) and S-iPTH were measured. Peripheral quantitative computed tomography measurements were taken at 4 and $66 \%$ of the forearm length. In all groups, the distribution of S-25OHD was shifted towards the lower limit of the normal range. A high prevalence of vitamin D insufficiency (S-25OHD $<50 \mathrm{nmol} / \mathrm{l}$ ) was observed (89.6\%) in the Somali group. The prevalence of SHPT (S-iPTH $>65 \mathrm{ng} / \mathrm{l}$ ) was higher $(79 \cdot 1 \%)$ in Somali women than in Finnish women $(16 \%)$. There was a significant association between S-25OHD and S-iPTH $(r-0 \cdot 49, P<0 \cdot 001)$. Ethnicity and S-25OHD together explained $30 \%$ of the variation in S-iPTH. The total bone mass at all sites of the forearm, fracture load and stress-strain index was higher $(P<0 \cdot 001)$ in Bangladeshi and Finnish women than in Somali women. The high prevalence of hypovitaminosis D, SHPT and low bone status in Somali women indicates a higher risk of osteoporosis.

\section{Key words: Bone mineral density: Immigrant women: Vitamin D deficiency: Parathyroid hormone}

Vitamin D deficiency has become epidemic for all age groups worldwide, and it has been estimated that about one billion people have either vitamin D deficiency or relative insufficiency. Vitamin D insufficiency is associated with metabolic bone disease and increases the risk for many common chronic diseases $^{(1)}$. Vitamin D is essential for the maintenance of $\mathrm{Ca}$ homeostasis and bone mineralisation. Vitamin D deficiency can result in osteomalacia and aggravate age-related bone loss, leading to osteoporosis ${ }^{(2)}$. Restricted sunlight exposure, reduced cutaneous synthesis of vitamin D and inadequate dietary intake are considered to be the main factors responsible for inadequate vitamin D status ${ }^{(3,4)}$. Serum 25-hydroxyvitamin D (S-25OHD) is the most commonly used index of vitamin $\mathrm{D}$ status because it gives information on the amount of vitamin $\mathrm{D}$ in the liver, the major tissue reserve of vitamin $\mathrm{D}^{(5)}$.

Seasonal variations in S-25OHD concentrations in northern latitudes have been reported previously. Due to the increased zenith angle of the sun, most solar UV-B photons are absorbed by the earth's ozone layer 4-6 months per year in winter (from October to March) and the skin makes little or no vitamin $\mathrm{D}_{3}$. Due to this high latitude and limited exposure to sunlight, populations living in Nordic countries are likely to be dependent on dietary sources of vitamin $\mathrm{D}$ to meet their biological needs during a considerable part of the year. The intake of fish, milk and milk products is very low in immigrant populations living in Europe ${ }^{(6)}$. Milk and margarine have been the major food sources fortified with vitamin D in Finland and adequate consumption of these food sources is necessary to meet the requirement. Studies from the UK, Norway and The Netherlands have suggested that immigrants are at risk for serious vitamin D deficiency and low bone mass compared with native inhabitants ${ }^{(6-10)}$. However, with no endogenous synthesis of vitamin D during winter together with inadequate dietary intake, immigrant women living in Finland may be

Abbreviations: BMD, bone mineral density; SHPT, secondary hyperparathyroidism; S-iPTH, serum intact parathyroid hormone; S-25OHD, serum 25-hydroxyvitamin D.

*Corresponding author: C. Lamberg-Allardt, fax +358 9 19158269, email christel.lamberg-allardt@helsinki.fi 
at particular risk for the deleterious effects of vitamin D insufficiency, which could result in low bone mass. The increase in morbidity associated with osteoporosis and other vitamin D deficiency-related health problems among these subjects may involve future strain of the health care system of Finland. However, to the best of our knowledge, no study has reported vitamin $\mathrm{D}$ and bone mineral density (BMD) status in immigrant women in Finland. Thus, it is of great interest to compare vitamin D and BMD status between ethnic Finnish and immigrant women.

The study was conducted in late winter (late January to February), when S-25OHD concentrations are lowest. The objectives of the present study were to determine the prevalence of hypovitaminosis $\mathrm{D}$ and high serum intact parathyroid hormone (S-iPTH) concentration levels in immigrant subjects compared with ethnic Finnish women. Since vitamin D status and S-iPTH levels affect BMD in adults, we also investigated the ethnic differences in forearm bone parameters at the distal and diaphyseal radius, using peripheral quantitative computed tomography in two groups of immigrant women of South Asian and African descent and compared the findings with that of Finnish women.

\section{Subjects and methods}

\section{Study setting and subjects}

The study was carried out in the Helsinki area $\left(60^{\circ} \mathrm{N}\right)$ during January-February 2008. A total of 143 subjects were recruited from two groups of immigrant women (Bangladeshi, $n 34$ and Somali, $n$ 48) and a group of ethnic Finnish women ( $n$ 61; Caucasian). The eligibility criteria for inclusion of subjects comprised no history of serious medical conditions, no history of medication known to affect bone metabolism, no current pregnancies and no lactation within the previous 2 years. The immigrant participants were mainly pre-menopausal Muslim women who had immigrated to Helsinki at least 3 years earlier. The background, objectives and recruitment criteria of the present study were written in Bangla, Finnish and Somali languages. Our first step was to contact the immigrant subjects through personal communication, family connections and a community network to explain the purpose of the study, supply them all information and to request their cooperation. We had an advertisement at the Helsinki University webpage in Finnish. The ethnic Finnish subjects mainly showed their interest for participation with this approach and communicated with us by telephone and email connection. The subjects were asked to consent to participate in the study. In some cases in the immigrant groups, permission of the husband was sought for the subjects to participate. The study protocol was approved by the ethics committee of the Hospital of the District of Helsinki and Uusimaa, Finland.

\section{Anthropometric measurements and other data}

Standing height (m) was measured, using a wall-mounted scale to the nearest $0.5 \mathrm{~cm}$. Body weight was measured without shoes and with light clothing on a weighing scale to the nearest $0.5 \mathrm{~kg}$. We used the classifications of BMI (weight $(\mathrm{kg}) /$ height $\left(\mathrm{m}^{2}\right)$ ) recommended by the $\mathrm{WHO}^{(11)}$. A complete questionnaire was developed regarding necessary information such as name, age, address, education level, parity, out-door clothing, frequency and duration of sunlight exposure, use of sunlight protection cream, medical history, use of vitamin D supplements within 3 months, etc. A FFQ was used to determine the dietary vitamin $\mathrm{D}$ intake from the last 1 month based on frequency of consumption of specific foods that are believed to contribute to the dietary intake of vitamin D. We have developed and validated a FFQ, which was used for the estimation of dietary intake of vitamin D in the Finnish population. For the present study, we further developed and validated the FFQ in a small group of subjects. Due to some limitations, estimation of dietary intake of vitamin $\mathrm{D}$ and collection of other background information was not possible in Bangladeshi subjects.

\section{Laboratory measurements}

Fasting blood samples were collected between 08.30 and 10.00 hours. The serum was preserved at $-20^{\circ} \mathrm{C}$ in the freezing room of the Division of Nutrition, Department of Food and Environmental Sciences, University of Helsinki until analysed.

S-25OHD was measured from all fasting samples with an OCTEIA immunoenzymometric assay (IDS, Boldon, UK). The intra- and inter-assay CV were 4.9 and $6.8 \%$, respectively. Reproducibility was ensured by adhering to the Vitamin D External Quality Assessment Scheme. Standardised concentrations of S-25OHD were provided. We defined vitamin D status as severely deficient when S-25OHD was $<25 \mathrm{nmol} / 1$, deficient when S-25-OHD was $<50 \mathrm{nmol} / 1$, insufficient when S-25-OHD was between 51 and $74 \mathrm{nmol} / 1$ and sufficient when S-25-OHD was $>75 \mathrm{nmol} / 1$, according to the reference values for an adult population ${ }^{(12,13)}$. The S-iPTH level was measured with a commercial two-site immunoenzymometric assay (OCTEIA, IDS), with $10-65 \mathrm{ng} / \mathrm{l}$ as a reference range. Intra- and inter-assay CV for iPTH were 3.8 and $5.7 \%$, respectively. We defined secondary hyperparathyroidism (SHPT) as S-iPTH levels $>65 \mathrm{ng} / \mathrm{l}$. The laboratory analysis was carried out at the Department of Food and Environmental Sciences.

\section{Peripheral quantitative computed tomography}

Peripheral quantitative computed tomography measurements were taken in the radius, using a Stratec XCT-2000 scanner (Stratec, Pforzheim, Germany), software version 5.50d. All measurements were taken in the non-dominant forearm at 4 and $66 \%$ of the forearm length (measured with a tape measure), proximal to the distal radial joint surface. The total bone mass $(\mathrm{g} / \mathrm{cm})$, total area $\left(\mathrm{mm}^{2}\right)$, cortical area $\left(\mathrm{mm}^{2}\right)$, trabecular density $\left(\mathrm{mg} / \mathrm{mm}^{3}\right)$ were determined at the radius $4 \%$ (distal) site. At the radius 66\% (proximal) site, total bone mass $(\mathrm{g} / \mathrm{cm})$, total area $\left(\mathrm{mm}^{2}\right)$, cortical area $\left(\mathrm{mm}^{2}\right)$, cortical density $\left(\mathrm{mg} / \mathrm{mm}^{3}\right.$ ), stress-strain index (a measure of bone torsional strength; $\mathrm{mm}^{3}$ ) and cortical area:total area ratio $\left(\mathrm{mm}^{2}\right)$ were measured. Phantom scans were executed daily to maintain quality assurance. The long-term CV for 
the phantom BMD and bone mineral content were 1.9 and $1 \cdot 1$, 2.7 and 0.79 and 0.50 and $0.78 \%$ in the total, cortical and trabecular bone, respectively. Short-term precision (CV\%) was determined with duplicate measurements of eight subjects. CV for the total BMD and bone mineral content were $4 \cdot 4$ and $4 \cdot 1$, respectively.

\section{Statistical analysis}

Statistical analyses were carried out with SPSS version 15.0 for Windows (SPSS, Inc., Chicago, IL, USA). Univariate analyses were performed for selected variables. The normal distribution of variables was assessed with a Kolmogorov-Smirnov test. If the data were not normally distributed, they were logarithmically transformed before further analysis. Ethnicity was used as a categorical variable as well as a dummy variable (Caucasian origin $=0$, non-Caucasian origin $=1$ ). Post boc tests were performed with Tukey's honestly significant different test and Dunnett's test. Bone data and other selected variables were tested with both ANOVA and ANCOVA to show the effect of confounding factors. To find a statistically significant differences, post hoc tests for ANCOVA were done by comparing if the $95 \%$ CI overlap. For each analysis, the covariates are mentioned in the tables. All data are reported as means and standard deviations; $P<0.05$ was considered significant.

\section{Results}

\section{Basic characteristics of the subjects}

There were statistically significant differences in anthropometric characteristics in the groups of immigrant women and ethnic Finnish women (Table 1). In Bangladeshi subjects, short stature was highly prevalent and the mean BMI value was slightly above the upper limit of the desired range. Somali subjects had a significantly higher BMI value $(P<0 \cdot 001)$ than Finnish subjects. We identified three levels of education (category $1=$ primary level, category $2=$ secondary level and category $3=$ above the secondary level) among the subjects. About $61 \%$ of the subjects in the Somali group had category 1 level of education. Less than $17 \%$ of the subjects in this group had category 3 level of education, whereas more than $98 \%$ of the subjects in both the Finnish and Bangladeshi groups had category 3 level of education. A significant group difference was apparent with respect to physical activity $(P<0 \cdot 001)$. No significant difference was observed in the dietary intake of vitamin D between Somali immigrants and ethnic Finnish women (Table 1).

\section{Serum 25-hydroxyvitamin D and intact parathyroid hormone concentration}

Of the 143 subjects studied, $117(81 \cdot 8 \%)$ had S-25OHD $<50$ $\mathrm{nmol} / \mathrm{l}$, which is generally considered the lower limit of the desired range. The mean concentrations of S-25OHD were significantly higher in Finnish women than in Bangladeshi $(P=0.005)$ and Somali women $(P<0.001)$. The proportion of subjects with vitamin $D$ insufficiency was predominantly higher in those of Somali descent than in those of Finnish and Bangladeshi descent (Table 2).

The Somali subjects showed significantly higher S-iPTH concentrations than the Bangladeshi and Finnish subjects $(P<0 \cdot 001)$. In comparison with subjects with a Finnish background, the prevalence of serious vitamin $\mathrm{D}$ deficiency defined as SHPT (S-iPTH levels $>65 \mathrm{ng} / \mathrm{l}$ ) was about five times higher $(79 \cdot 1 \%)$ in subjects with a Somali background and two times higher $(31.5 \%)$ in subjects with a Bangladeshi background. There was a strong inverse linear correlation between $\ln$ S-25OHD and $\ln$ S-iPTH $(r=-0 \cdot 49, P<0.001)$. In linear regression analysis, one unit increase in S-25OHD on the $\ln$ scale decreased S-iPTH on the $\ln$ scale by 0.59 units. The model $(\ln \mathrm{S}$-iPTH $=6.286-0.593 \times \ln \mathrm{S}-25 \mathrm{OHD})$ explained $24 \%$ of the variation in $\mathrm{S}-\mathrm{iPTH}$. Calculated from the equation, the mean S-iPTH concentration (64ng/l) was reached at S-25OHD concentrations above $36 \mathrm{nmol} / \mathrm{l}$ (Fig. 1). In multivariate regression analysis, S-25OHD and ethnicity together explained $30 \%$ of the variation in S-iPTH. In the whole study, $37 \%$ of the subjects had S-25OHD values below $36 \mathrm{nmol} / 1$.

Table 1. Characteristics of the randomly assigned groups

(Mean values and standard deviations)

\begin{tabular}{|c|c|c|c|c|c|c|c|c|c|}
\hline \multirow{2}{*}{$\begin{array}{l}\text { Physical, biochemical and } \\
\text { other characteristics }\end{array}$} & \multicolumn{2}{|c|}{ Bangladeshi (n 34) } & \multicolumn{2}{|c|}{ Somali ( $n$ 48) } & \multicolumn{2}{|c|}{ Finnish ( $n$ 61) } & \multirow[b]{2}{*}{$P^{*}$} & \multirow[b]{2}{*}{$P \dagger$} & \multirow[b]{2}{*}{$P \ddagger$} \\
\hline & Mean & SD & Mean & SD & Mean & SD & & & \\
\hline Age (years) & 32.5 & $6 \cdot 7$ & $36 \cdot 0$ & $6 \cdot 2$ & $28 \cdot 6$ & 3.7 & 0.006 & 0.000 & 0.008 \\
\hline Weight $(\mathrm{kg})$ & $66 \cdot 4$ & $14 \cdot 7$ & $71 \cdot 4$ & $14 \cdot 6$ & $62 \cdot 6$ & $10 \cdot 3$ & 0.538 & 0.002 & 0.265 \\
\hline Height (cm) & $157 \cdot 1$ & $6 \cdot 0$ & 161.9 & $5 \cdot 1$ & $167 \cdot 7$ & $5 \cdot 3$ & 0.000 & 0.000 & 0.000 \\
\hline $\mathrm{BMI}\left(\mathrm{kg} / \mathrm{m}^{2}\right)$ & $26 \cdot 8$ & $5 \cdot 1$ & $27 \cdot 3$ & 5.9 & $22 \cdot 2$ & 3.4 & 0.000 & 0.000 & 0.964 \\
\hline Dietary intake of vitamin $D(\mu \mathrm{g} / \mathrm{d})$ & - & - & $5 \cdot 0$ & $2 \cdot 0$ & 4.6 & $2 \cdot 0$ & - & 0.308 & - \\
\hline Physical activity (min/d) & - & - & $47 \cdot 3$ & 24.4 & $73 \cdot 0$ & $42 \cdot 0$ & - & 0.000 & - \\
\hline S-25OHD (nmol/l) & $42 \cdot 9$ & $16 \cdot 1$ & $36 \cdot 8$ & $11 \cdot 8$ & $54 \cdot 1$ & $19 \cdot 1$ & 0.005 & 0.000 & $0.282 \S$ \\
\hline S-iPTH (ng/l) & $57 \cdot 8$ & $17 \cdot 6$ & 85.5 & 31.6 & $50 \cdot 7$ & 23.4 & 0.583 & 0.000 & $0.000 \|$ \\
\hline
\end{tabular}

S-25OHD, serum 25-hydroxyvitamin D; S-iPTH, serum intact parathyroid hormone.

${ }^{*}$ Finnish $v$. Bangladeshi.

†Finnish $v$. Somali.

¥Somali $v$. Bangladeshi.

$\S P$ value adjusted for ethnicity.

$\| P$ value adjusted for S-25OHD and ethnicity. 
Table 2. Distribution of vitamin $D$ status in subjects: the percentage of subjects in different groups with serum 25-hydroxyvitamin $D$ (S-25OHD) concentrations below and above predefined cut-offs

(Numbers and percentages)

\begin{tabular}{|c|c|c|c|c|c|c|c|}
\hline \multirow[b]{2}{*}{ S-25OHD (nmol/l) } & \multirow[b]{2}{*}{ Vitamin D status } & \multicolumn{2}{|c|}{ Bangladeshi ( $n$ 34) } & \multicolumn{2}{|c|}{ Somali $(n 48)$} & \multicolumn{2}{|c|}{ Finnish ( $n 61)$} \\
\hline & & $n$ & $\%$ & $n$ & $\%$ & $n$ & $\%$ \\
\hline$<25$ & Severely deficient & - & 0 & 4 & 8.3 & 2 & $3 \cdot 3$ \\
\hline $25-50$ & Deficient & 24 & $70 \cdot 6$ & 39 & $81 \cdot 3$ & 27 & $44 \cdot 3$ \\
\hline $51-74$ & Insufficient & 8 & 23.5 & 4 & 8.3 & 21 & 34.4 \\
\hline$>75$ & Sufficient & 2 & 5.9 & 1 & $2 \cdot 1$ & 11 & $18 \cdot 0$ \\
\hline
\end{tabular}

\section{Bone traits}

Bone variables at most of the sites of the forearm were significantly higher in the Finnish women (Table 3). Most bone traits were significantly lower in the Somali group than in the other groups. In all ethnic groups of the present study, there was a significant correlation between S-25OHD concentrations and distal and proximal radius BMD $(r 0 \cdot 25, P=0.008$ and $r 0 \cdot 27$, $P=0 \cdot 001$, respectively) and the stress-strain index $(r 0.27$, $P=0.001$ ) after adjusting for age. We observed a progressive increase in all variables describing forearm bone mass with high S-25OHD concentrations (Table 4).

\section{Discussion}

To the best of our knowledge, the present study is the first to detail the prevalence of hypovitaminosis D, SHPT and forearm bone status among pre-menopausal immigrant women and compare the data with those of ethnic Finnish women. We observed the relationship between S-25OHD, S-iPTH and forearm bone mass in these subject groups.

The problem of high prevalence of hypovitaminosis D and vitamin D deficiency among Europeans is not a new finding. Substantial studies have been carried out since 1970 among ethnic European and immigrant populations. Immigrant status has been reported to be an additional risk factor for vitamin D deficiency. However, the most important finding in the present study was the unexpectedly high prevalence of hypovitaminosis $\mathrm{D}(\mathrm{S}-25 \mathrm{OHD}<50 \mathrm{nmol} / \mathrm{l})$ in both immigrants and ethnic Finnish subjects. Subjects with the Somali background were the most vulnerable group in the present study, since low S-25OHD concentrations were most frequently observed in these subjects.

In fact, low S-25OHD is a matter of concern, because it has clinical importance and may result in SHPT and increased bone loss. In the present study, we observed severe vitamin $\mathrm{D}$ depletion in the immigrants, Somali subjects in particular. The lower S-25OHD concentrations in this group may trigger higher S-iPTH concentrations that may stimulate bone resorption in these subjects. The present data confirm the high prevalence of vitamin D insufficiency and SHPT among female immigrant populations living in Helsinki $\left(60^{\circ} \mathrm{N}\right)$, which is also in line with previous studies among immigrants in Denmark, Norway and The Netherlands ${ }^{(6,9,14-17)}$. The data also indicate the most adverse impact of vitamin D insufficiency on forearm bone status among Somali subjects.
In the present study, we observed that higher dietary vitamin D intake was not associated with higher S-25OHD concentrations (Table 1). The results of previous studies also indicated that dietary vitamin $\mathrm{D}$ intake became less of a contributing factor to vitamin D status when supplement consumption and sunlight exposure were increased ${ }^{(18,19)}$. Although $50 \%$ of the subjects in the Finnish group reported their intake of vitamin D supplements within 3 months, the rate of supplement consumption was very low in immigrant subjects. Only three in the Bangladeshi group and five in the Somali group reported their intake of vitamin D supplements. In Helsinki, Finland $\left(60^{\circ} \mathrm{N}\right)$, no UV-B radiation is found between 15 October and 15 March. Due to this high latitude and limited exposure to sunlight, cutaneous vitamin D production is absent during part of the year, so that the population living in this area is likely to be dependent on dietary sources of vitamin D. Since the natural sources of vitamin D are limited, consumption of vitamin D supplement was also recommended for this population during winter. However, the low dietary intake of vitamin D, no use of vitamin D supplements and no cutaneous vitamin $\mathrm{D}$ production in winter are probably the underlying reasons for the unexpectedly high prevalence of vitamin D insufficiency among immigrant subjects.

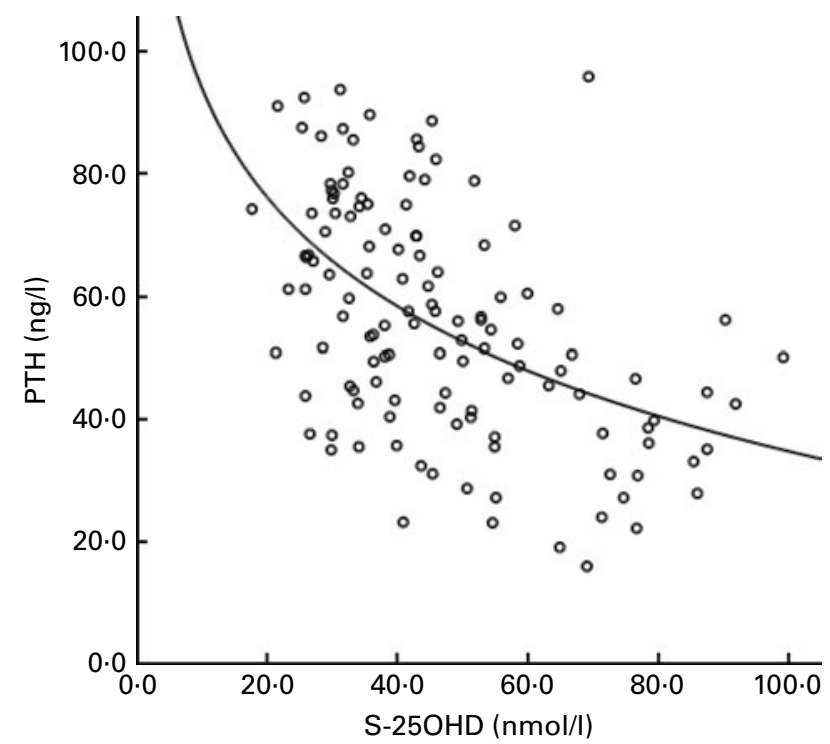

Fig. 1. Association between serum 25-hydroxyvitamin D (S-25OHD) and serum intact parathyroid hormone (PTH) concentrations in a non-linear regression model. $\mathrm{PTH}=153-25.7 \times \ln (\mathrm{S}-25 \mathrm{OHD}), R^{2} 26, P<0.0005$. 
Table 3. Ethnic differences in forearm bone variables of the randomly assigned groups

(Mean values and standard deviations)

\begin{tabular}{|c|c|c|c|c|c|c|c|c|c|}
\hline \multirow[b]{2}{*}{ Forearm bone parameters } & \multicolumn{2}{|c|}{ Bangladeshi (n 34) } & \multicolumn{2}{|c|}{ Somali $(n$ 48) } & \multicolumn{2}{|c|}{ Finnish ( $n$ 61) } & \multirow[b]{2}{*}{$P^{*}$} & \multirow[b]{2}{*}{$P \dagger$} & \multirow{2}{*}{$\begin{array}{c}\text { Covariance } \\
\text { analysis }\end{array}$} \\
\hline & Mean & SD & Mean & SD & Mean & SD & & & \\
\hline \multicolumn{10}{|c|}{ Distal radius (measurement at $4 \%$ of the forearm length) } \\
\hline Total bone mass $(\mathrm{g} / \mathrm{cm})$ & 0.999 & 0.132 & 0.919 & 0.114 & $1 \cdot 028$ & $0 \cdot 136$ & 0.095 & 0.000 & $<0.001 \S$ \\
\hline Total area $\left(\mathrm{mm}^{2}\right)$ & $289 \cdot 8$ & $49 \cdot 6$ & $266 \cdot 7$ & $40 \cdot 0$ & $309 \cdot 2$ & $45 \cdot 4$ & 0.142 & 0.000 & $<0.001 \|$ \\
\hline Cortical area $\left(\mathrm{mm}^{2}\right)$ & $159 \cdot 5$ & $27 \cdot 2$ & $146 \cdot 8$ & $22 \cdot 0$ & $170 \cdot 2$ & $25 \cdot 0$ & $0 \cdot 142$ & 0.000 & $<0.001 \S$ \\
\hline Trabecular density $\left(\mathrm{mg} / \mathrm{cm}^{3}\right)$ & $170 \cdot 51$ & $38 \cdot 38$ & $166 \cdot 91$ & $29 \cdot 98$ & $176 \cdot 05$ & 32.49 & 0.743 & 0.373 & 0.550 \\
\hline \multicolumn{10}{|c|}{ Proximal radius (measurement at $66 \%$ of the forearm length) } \\
\hline Total bone mass $(\mathrm{g} / \mathrm{cm})$ & 0.850 & 0.114 & 0.839 & 0.099 & 0.975 & 0.116 & 0.000 & 0.000 & $<0.001 \S$ \\
\hline Total area $\left(\mathrm{mm}^{2}\right)$ & $115 \cdot 7$ & $20 \cdot 1$ & $106 \cdot 2$ & $15 \cdot 3$ & $126 \cdot 2$ & 18.4 & 0.023 & 0.000 & $<0.001 \|$ \\
\hline Cortical area $\left(\mathrm{mm}^{2}\right)$ & 63.7 & $9 \cdot 2$ & $61 \cdot 7$ & $7 \cdot 8$ & 74.0 & $9 \cdot 2$ & 0.000 & 0.000 & $<0.001 \S$ \\
\hline Cortical density $\left(\mathrm{mg} / \mathrm{cm}^{3}\right)$ & $1118 \cdot 98$ & $28 \cdot 71$ & $1140 \cdot 14$ & 31.94 & $1146 \cdot 34$ & $29 \cdot 12$ & 0.000 & 0.880 & $<0.0019$ \\
\hline Stress-strain index $\left(\mathrm{mm}^{3}\right)$ & 271.40 & 54.00 & $193 \cdot 31$ & $45 \cdot 89$ & $268 \cdot 34$ & $50 \cdot 12$ & 0.000 & 0.000 & $<0.001 \|$ \\
\hline Cortical area:total area ratio $\left(\mathrm{mm}^{2}\right)$ & 0.558 & 0.076 & 0.582 & 0.069 & 0.592 & 0.068 & 0.066 & 1.000 & 0.130 \\
\hline
\end{tabular}

* Finnish v. Bangladeshi.

† Finnish v. Somali.

$\ddagger P$ value adjusted for height.

$\S$ Somali $v$. Finnish.

Somali $v$. Finnish and Bangladeshi.

I Bangladeshi $v$. Somali and Finnish.

Several studies ${ }^{(20,21)}$ have reported that vitamin D deficiency may cause SHPT and low bone mass among women, which agree with the present findings in immigrant women. However, our findings among the subjects with a Finnish background were in contrast to these results and agree with reports suggesting that low S-25OHD does not always lead to an increase in the level of S-iPTH ${ }^{(22,23)}$. In fact, a comparison of the present findings on S-25OHD and S-iPTH with previous studies may not be fully appropriate, because the studies were conducted in different seasons, with subject groups of varying ethnic backgrounds and using various commercial assays in different laboratories.
The negative association between S-25OHD and S-iPTH is commonly used to establish an adequate serum vitamin D concentration. There is some disagreement concerning the S-25OHD concentrations that trigger the increase in S-iPTH, which varies from 30 to $125 \mathrm{nmol} / 1$ for S-25OHD ${ }^{(22,24-26)}$ Some researchers ${ }^{(22,27)}$ have concluded that S-25OHD of $>80 \mathrm{nmol} / \mathrm{l}$ was required to obtain maximal intestinal $\mathrm{Ca}$ absorption. Holick et $a l .{ }^{(28)}$ also reported that their consistent findings on S-25OHD for maximal intestinal Ca absorption. Malabanan et al. ${ }^{(29)}$ concluded that S-25OHD concentration of $50 \mathrm{nmol} / \mathrm{l}$ was the minimum value required to optimise $\mathrm{S}$-iPTH levels and prevent SHPT. There is no disagreement

Table 4. Differences in forearm bone variables, and physical and biochemical variables in the subjects divided into two categories according to serum 25 -hydroxyvitamin D (S-25OHD) concentration ( $\leq 36$ or $>36 \mathrm{nmol} / \mathrm{l}$ )

(Mean values and standard deviations)

\begin{tabular}{|c|c|c|c|c|c|}
\hline \multirow[b]{3}{*}{ Forearm bone parameters } & \multicolumn{4}{|c|}{$\mathrm{S}-25 \mathrm{OHD}(\mathrm{nmol} / \mathrm{l})$} & \multirow[b]{3}{*}{$P$} \\
\hline & \multicolumn{2}{|c|}{$\leq 36(n 53)$} & \multicolumn{2}{|c|}{$>36(n 90)$} & \\
\hline & Mean & SD & Mean & SD & \\
\hline \multicolumn{6}{|c|}{ Distal radius (measurement at $4 \%$ of the forearm length) } \\
\hline Total bone mass $(\mathrm{g} / \mathrm{cm})$ & 0.962 & 0.136 & 1.000 & 0.135 & 0.115 \\
\hline Total area $\left(\mathrm{mm}^{2}\right)$ & $286 \cdot 84$ & $52 \cdot 34$ & 293.07 & $45 \cdot 59$ & 0.461 \\
\hline Cortical area $\left(\mathrm{mm}^{2}\right)$ & $157 \cdot 9$ & 28.7 & $161 \cdot 3$ & $25 \cdot 0$ & 0.460 \\
\hline Trabecular density $\left(\mathrm{mg} / \mathrm{cm}^{3}\right)$ & 171.08 & $30 \cdot 07$ & $172 \cdot 14$ & $35 \cdot 13$ & 0.849 \\
\hline \multicolumn{6}{|c|}{ Proximal radius (measurement at $66 \%$ of the forearm length) } \\
\hline Total bone mass $(\mathrm{g} / \mathrm{cm})$ & 0.863 & $0 \cdot 127$ & 0.923 & 0.122 & 0.006 \\
\hline Total area $\left(\mathrm{mm}^{2}\right)$ & 112.49 & 19.42 & $120 \cdot 03$ & $19 \cdot 61$ & 0.028 \\
\hline Cortical area $\left(\mathrm{mm}^{2}\right)$ & $64 \cdot 2$ & $10 \cdot 2$ & 69.5 & $10 \cdot 1$ & 0.003 \\
\hline Cortical density $\left(\mathrm{mg} / \mathrm{cm}^{3}\right)$ & $1132 \cdot 83$ & 31.38 & $1140 \cdot 91$ & 31.66 & 0.144 \\
\hline Stress-strain index $\left(\mathrm{mm}^{3}\right)$ & $212 \cdot 83$ & $57 \cdot 74$ & $243 \cdot 16$ & $58 \cdot 23$ & 0.003 \\
\hline Cortical area:total area ratio $\left(\mathrm{mm}^{2}\right)$ & 0.578 & 0.07 & 0.590 & 0.07 & 0.560 \\
\hline \multicolumn{6}{|l|}{ Physical and biochemical characteristics } \\
\hline Age (years) & $32 \cdot 6$ & $6 \cdot 9$ & 31.6 & $5 \cdot 9$ & 0.380 \\
\hline Height $(\mathrm{cm})$ & $161 \cdot 1$ & 6.9 & 161.8 & $6 \cdot 7$ & 0.055 \\
\hline Weight (kg) & 67.0 & $11 \cdot 8$ & $66 \cdot 1$ & $14 \cdot 3$ & 0.681 \\
\hline $\operatorname{BMI}\left(\mathrm{kg} / \mathrm{m}^{2}\right)$ & $25 \cdot 6$ & $4 \cdot 7$ & $24 \cdot 6$ & 5.6 & $0 \cdot 251$ \\
\hline S-iPTH (ng/l) & 77.9 & $31 \cdot 2$ & $55 \cdot 9$ & 25.5 & 0.000 \\
\hline $\mathrm{S}-25 \mathrm{OHD}(\mathrm{nmol} / \mathrm{l})$ & 29.7 & $4 \cdot 3$ & $55 \cdot 0$ & $16 \cdot 1$ & 0.000 \\
\hline
\end{tabular}

S-iPTH, serum intact parathyroid hormone. 
concerning the association between the S-25OHD and S-iPTH concentrations. The correlation coefficient between the two indices is of relatively low magnitude, indicating that only a small part of variation in S-iPTH concentration is explained by the differences in S-25OHD concentrations. The present study indicated that S-25OHD and ethnicity together explained $30 \%$ of the variation in S-iPTH and $24 \%$ of the total variability in S-iPTH was explained by the variation in S-25OHD alone. Thus, the present results suggest that to maintain S-iPTH in balance throughout the year to prevent SHPT and to maintain healthy bone mass, S-25OHD concentrations could be considered as one of the important factors and should be maintained at a sufficient level throughout the year, both for immigrants and ethnic Finnish women.

Debate over the most appropriate cut-off value for identifying vitamin D deficiency or insufficiency is still open. However, most experts recommended at a recent consensus conference that serum concentrations of vitamin $\mathrm{D}$ higher than $75 \mathrm{nmol} / 1$ may be associated with better health outcomes in terms of higher BMD and less risk of many common and serious diseases, including osteoporosis, some common cancers, type 1 diabetes, multiple sclerosis, rheumatoid arthritis, schizophrenia and CVD. If the $75 \mathrm{nmol} / 1$ cut-off for the present study subjects is used, only $9 \%$ of the subjects would enjoy optimal S-25OHD concentrations in winter. The US Institute of Medicine ${ }^{(30)}$ suggested S-25OHD levels of $50 \mathrm{nmol} / 1$ to cover the requirements of $97 \%$ of the population. We observed that only $32 \%$ of the subjects had this level of S-25OHD.

The present data are consistent with previous findings ${ }^{(10,14,17,31,32)}$ in European countries and elsewhere that female immigrants with Asian and African backgrounds have a high prevalence of S-25OHD insufficiency. In terms of the relationship between S-25OHD and S-iPTH or BMD, there are conflicting results observed in previous studies. However, a remarkable number of studies ${ }^{(33-37)}$ have shown the positive correlation between S-25OHD and BMD. Vitamin $\mathrm{D}$ insufficiency influences bone mass in ethnic Finnish subjects and the present data are consistent with this finding ${ }^{(19,38)}$.

In all ethnic groups of the present study, there was a significant correlation among S-25OHD concentrations and several bone traits. This suggests that subclinical vitamin $\mathrm{D}$ deficiency could be a factor responsible for weak bones with low bone mass and a risk factor for osteoporosis.

\section{Limitations to the study}

The subjects included in the present study may have vitamin D status different from that of the population in general. A population-based study and random selection criteria of subjects could provide better evidence on vitamin D status. We used the reference range for S-iPTH (10-65 ng/l) and the thresholds for SHPT ( $>65 \mathrm{ng} / \mathrm{l})$ given by the manufacturer of the assay, which is controversial. The frequency of SHPT in the different subgroups studied and the concentration of $25 \mathrm{OHD}$, at which the curved regression line between S-iPTH and S-25OHD cuts the line separating 'normal parathyroid hormone' concentration from SHPT (Fig. 1), could have been increased significantly if a lower and more authentic cut-off level for SHPT is used ${ }^{(39,40)}$.

\section{Conclusions}

Regardless of the ethnic background, the present data confirm the unexpectedly high prevalence of vitamin D deficiency or insufficiency during winter among immigrant women and ethnic Finnish women. In the present study, Somali subjects were the most vulnerable group at risk of low bone mass, osteomalacia and osteoporosis. Public health measures to increase the level of S-25OHD and to prevent SHPT are urgently required. Therefore, both health policy makers and health professionals should pay attention without delay to this silent epidemic. To prevent vitamin D deficiency during winter, the increased consumption of vitamin D-rich food, such as fish, and consumption of vitamin D supplements are recommended. An immediate plan to maintain optimal vitamin $\mathrm{D}$ status and gain increased bone mass could prove beneficial in alleviating future strain on the health care system of Finland by reducing morbidity caused by osteoporosis and other problems related to vitamin D deficiency. The present results suggest that an intervention trial to improve vitamin $\mathrm{D}$ and BMD status and to minimise osteoporotic risk is essential in these segments of the population.

\section{Acknowledgements}

The present study was supported by a research grant of the Ella and Georg Ehrnrooth Foundation, Finland. The authors are grateful to members of the directory board of the foundation. We thank the 143 volunteer subjects who participated in the study, making the research possible. Md Z. I., C. L.-A. and K. L. designed the study, secured funding and participated in carrying out the study. Md Z. I. was the principal investigator of the study, providing guidance in data collection and participating in data entry, statistical analysis and writing the manuscript. H. T. V. and E. S. contributed to field data collection. C. L.-A. checked the manuscript and approved the final version. M. U. M. K. participated in the statistical analysis and interpretation. None of the contributing authors had any financial or personal conflicts of interest.

\section{References}

1. Holick MF (2006) High prevalence of vitamin D inadequacy and implications for health. Mayo Clin Proc 81, 353-373.

2. Chapuy MC, Arlot ME, Duboeuf F, et al. (1992) Vitamin $D_{3}$ and calcium to prevent hip fractures in elderly women. $N$ Eng J Med 327, 1637-1642.

3. Webb AR, Pilbeam C, Hanafin N, et al. (1990) An evaluation of the relative contributions of exposure to sunlight and of diet to the circulating concentrations of 25-hydroxyvitamin $\mathrm{D}$ in an elderly nursing home population in Boston. Am J Clin Nutr 51, 1075-1081.

4. Salamone LM, Dallal GE, Zantos D, et al. (1994) Contributions of vitamin $\mathrm{D}$ intake and seasonal sunlight exposure to plasma 25-hydroxyvitamin D concentration in elderly women. Am J Clin Nutr 59, 80-86. 
5. Fraser DR (1983) The physiological economy of vitamin D. Lancet i, 969-972.

6. Henriksen C, Brunvand L, Stoltenberg C, et al. (1995) Diet and vitamin D status among pregnant Pakistani women in Oslo. Eur J Clin Nutr 49, 211-218.

7. Ong SP, Ryley J, Bashir T, et al. (1983) Nutrient intake and associated biochemical status of pregnant Asians in the United Kingdom. Hum Nutr Appl Nutr 37, 23-29.

8. Lawson M, Thomas M \& Hardiman A (1999) Dietary and lifestyle factors affecting plasma vitamin D levels in Asian children living in England. Eur J Clin Nutr 53, 268-272.

9. Meyer HE, Falch JA, Sogaard AJ, et al. (2004) Vitamin D deficiency and secondary hyperparathyroidism and the association with bone mineral density in persons with Pakistani and Norwegian background living in Oslo, Norway, The Oslo Health Study. Bone 35, 412-417.

10. Roy DK, Berry JL, Pye SR, et al. (2006) Vitamin D status and bone mass in UK South Asian women. Bone 40, 200-204.

11. World Health Organization (2000) The Asia Pacific Perspective - Redefining Obesity and its Treatment. Sydney: International Diabetes Institute Health Communications Australia.

12. Holick MF (2006) High prevalence of vitamin D inadequacy and implications for health. Mayo Clin Proc 81, 353-373.

13. Bischoff-Ferrari HA, Giovannucci E, Willett WC, et al. (2006) Estimates of optimal serum concentrations of 25-hydroxyvitamin D for multiple health outcomes. Am J Clin Nutr 84, 18-28.

14. Holvik K, Meyer HE, Haug E, et al. (2005) Prevalence and predictors of vitamin D deficiency in five immigrant groups living in Oslo, Norway: the Oslo Immigrant Health Study. Eur J Clin Nutr 59, 57-63.

15. Andersen R, Molgaard C, Skovgaard LT, et al. (2008) Pakistani immigrant children and adults in Denmark have severely low vitamin D status. Eur J Clin Nutr 62, 625-634.

16. Van der Meer IM, Karamali NS, Boeke AJP, et al. (2006) High prevalence of vitamin D deficiency in pregnant non-Western women in The Hague, Netherlands. Am J Clin Nutr 84, 350-353.

17. Madar AA, Stene LC \& Meyer HE (2009) Vitamin D status among immigrant mothers from Pakistan, Turkey and Somalia and their infants attending child health clinics in Norway. Br J Nutr 101, 1052-1058.

18. Jacques PF, Felson DT, Tucker KL, et al. (1997) Plasma 25-hydroxyvitamin D and its determinants in an elderly population sample. Am J Clin Nutr 66, 929-936.

19. Outila TA, Karkkainen MU \& Lamberg-Allardt C (2001) Vitamin D status affects serum parathyroid hormone concentrations during winter in female adolescents: associations with forearm bone mineral density. Am J Clin Nutr $\mathbf{7 4}$, 206-210.

20. Serhan E \& Holland MR (2002) Relationship of hypovitaminosis $\mathrm{D}$ and secondary hyperparathyroidism with bone mineral density among UK resident Indo-Asians. Ann Rheum Dis 61, 456-458.

21. Sakuma M, Endo N, Oinuma T, et al. (2006) Vitamin D and intact PTH status in patients with hip fracture. Osteoporosis Int 17, 1608-1614.

22. Chapuy Preziosi P, Maamer M, Arnaud S, et al. (1997) Prevalence of vitamin D insufficiency in an adult normal population. Osteoporos Int 7, 439-443.

23. Islam MZ, Shamim AA, Kemi V, et al. (2008) Vitamin D deficiency and low bone status: grave concern in normal adult female garment factory workers in Bangladesh. $\mathrm{Br} \mathrm{J}$ Nutr 99, 1322-1329.

24. Grant WB \& Holick MF (2005) Benefits and requirements of vitamin D for optimal health: a review. Altern Med Rev 10, 94-111.

25. Kinuamy HK, Gallagher JC, Rafferty KA, et al. (1998) Dietary calcium and vitamin D intake in elderly women: effect on serum parathyroid hormone and vitamin D metabolites. Am J Clin Nutr 67, 342-348.

26. Lamberg-Allardt C, Outila TA, Kärkkäinen MUM, et al. (2001) Vitamin D deficiency and bone in healthy adults in Finland could this be a concern in other parts of Europe. $J$ Bone Miner Res 16, 2066-2073.

27. Heaney RP, Dowell MS, Hale CA, et al. (2003) Calcium absorption varies within the reference range for serum 25-hydroxyvitamin D. J Am Coll Nutr 22, 142-146.

28. Holick MF, Siris ES, Binkley N, et al. (2005) Prevalence of vitamin D inadequacy among postmenopausal North American women receiving osteoporosis therapy. J Clin Endocrinol Metab 90, 3215-3224.

29. Malabanan A, Veronikis E \& Holick MF (1998) Redefining vitamin D insufficiency. Lancet 351, 805-806.

30. Institute of Medicine (2011) Dietary Reference Intakes for Calcium and Vitamin D. Washington, DC: The National Academies Press.

31. Proto G (2008) Severe vitamin D deficiency and secondary hyperparathyroidism in two immigrant women in Italy. Minerva Endocrinol 33, 397-398.

32. Huntington MK, Shafer CW, Pudwill R, et al. (2010) Prevalence of vitamin D deficiency among immigrants to South Dakota. S D Med 63, 51-55.

33. Arya V, Bhambri R, Godbole MM, et al. (2004) Vitamin D status and its relationship with bone mineral density in healthy Asian Indians. Osteoporos Int 15, 56-61.

34. Scharla SH, Scheidt-Nave C, Leidig G, et al. (1996) Lower serum 25-hydroxyvitamin $\mathrm{D}$ is associated with increased bone resorption markers and lower bone density at the proximal femur in normal females: a population-based study. Exp Clin Endocrinol Diabetes 104, 289-292.

35. Fradinger EE \& Zanchetta JR (2001) Vitamin D and bone mineral density in ambulatory women living in Buenos Aires, Argentina. Osteoporos Int 12, 24-27.

36. Malavolta N, Pratelli L, Frigato M, et al. (2005) The relationship of vitamin D status to bone mineral density in an Italian population of postmenopausal women. Osteoporos Int 16, 1691-1697.

37. Viljakainen HT, Natri AM, Kärkkäinen M, et al. (2006) A positive dose-response effect of vitamin D supplementation on site-specific bone mineral augmentation in adolescent girls - a double-blinded randomized placebo-controlled one year intervention. J Bone Miner Res 21, 836-844.

38. Lehtonen-Veromaa MKM, Mottonen TT, Nuotio IO, et al. (2002) Vitamin D and attainment of peak bone mass among peripubertal Finnish girls: a 3 year prospective study. Am J Clin Nutr 76, 1446-1453.

39. Rejnmark L, Vestergaard P, Heickendorfft L, et al. (2011) Determinants of plasma PTH and their implication for defining a reference interval. Clin Endocrinol 74, 37-43.

40. Souberbielle J-C, Cormier C, Kindermans C, et al. (2001) Vitamin D status and redefining serum parathyroid hormone reference range in the elderly. J Clin Endocrinol Metab 86, 3086-3090. 